$5 \quad{ }^{1}$ University Hospitals of Leicester NHS Trust and University of Leicester, Dept of

6 Cardiovascular Sciences, Anaesthesia Critical Care \& Pain Management Group, 4th Floor,

7 Robert Kilpatrick Clinical Sciences Building, Leicester Royal Infirmary, Leicester, LE2 7LX, UK.

$8 \quad 2$ Blatchford Clinical Services, Leicester Specialist Mobility Centre, 17A Meridian East

9 Leicester, LE19 1WZ, UK.

\section{DEVELOPMENT OF A SCORING TOOL (BLART SCORE) TO PREDICT FUNCTIONAL OUTCOME IN LOWER LIMB AMPUTEES}

Sarah Bowrey ${ }^{1}$, Helen Naylor ${ }^{2}$, Pip Russell ${ }^{2}$, Jonathan Thompson ${ }^{1}$

Correspondence to: Professor Jonathan Thompson,

Dept of Cardiovascular Sciences, Anaesthesia Critical Care \& Pain Management Group, 4th Floor, Robert Kilpatrick Clinical Sciences Building, Leicester Royal Infirmary, Leicester, LE2 7LX, UK.

Tel: (+44) 01162523132

Fax: (+44) 01162523125

E-mail: jt23@le.ac.uk

\section{Keywords:}

amputees; assessment; leg; mobility; prosthesis.

Hon. Professor of Anaesthesia and Critical Care,

University of Leicester,

Dept of Cardiovascular Sciences,

Anaesthesia Critical Care \& Pain Management,

4th Floor, Robert Kilpatrick Clinical Sciences Building,

Leicester Royal Infirmary, Leicester, LE2 7LX, UK 
2 Purpose: To develop a valid pre-operative scoring tool that predicts the probability of

3 walking with a prosthetic limb after major lower limb amputation.

4 Methods: A retrospective review of 338 patients who had undergone lower limb 5 amputation was conducted to identify characteristics that affected the success of 6 rehabilitation with a prosthetic limb. These data were used to devise an assessment tool 7 (the BLARt score), which was then tested and validated in 199 patients planned to undergo 8 lower limb amputation in two UK regional centres. Functional rehabilitation outcomes were 9 recorded at 12 months after surgery using the SIGAM mobility grading.

Results: At 12 months after amputation, no patient with a BLARt score $\geq 13$ was able to walk independently (good functional outcome, SIGAM grade E or F); no patient with a BLARt score $\geq 22$ and only 6 patients with a BLARt score $\geq 17$ were able to walk to any degree

13 ('functional' outcome: SIGAM grade C or greater). The area-under the ROC for predicting inability to walk (poor functional outcome, SIGAM A or B) was 0.914 (SE 0.2) (95\% confidence intervals 0.87-0.95).

Conclusions: In the patient cohorts studied, the BLARt assessment tool was a strong predictor of patients' inability to walk with a prosthetic limb after surgery. It is simple to administer and could be useful in clinical practice to inform expectations for patients and clinicians. 
2

3

4

5

6

7

8

9

10

11

12

13

- Patients undergoing lower limb amputation face major physical and psychological challenges after surgery that have a considerable impact on rehabilitation and their ability to walk independently.

- Many amputees are unable able to walk with a prosthetic limb, but there are no validated tools to predict this before surgery.

- The BLARt is a potentially valuable measure that can predict the likelihood of being unable to walk after amputation.

- It is simple to use and could be useful to inform patients' and clinicians' expectations before surgery 
2 Recent estimates suggest that approximately 5000 people in the UK and 50,000 in the USA

3

4 worldwide because many countries do not keep accurate data. Most lower limb amputations (80\%) are performed for peripheral vascular disease; $40 \%$ of these are performed in diabetics. ${ }^{3}$ Other common indications are trauma, malignancy, congenital deformities and in extreme cases, chronic pain.

Major lower limb amputation has a huge impact on a patient's physical capabilities, quality of life and requires many adjustments to daily life. ${ }^{4}$ The importance of being able to estimate an individual's potential to walk with a prosthesis after amputation has been recognised. ${ }^{5}$ Effective rehabilitation to achieve independent walking with a prosthetic limb is physically and mentally challenging. The ability to walk independently with a prosthesis is determined by several factors, including patient age, physical fitness, the presence of associated injuries or co-morbidities, patient motivation, social circumstances and the availability of support. ${ }^{6}$ The reliability, comfort, ease of use and functionality of the prosthesis are also important. ${ }^{2}$

Accurate and informed information should be at the heart of decision-making before amputation. ${ }^{7}$ However, it is difficult to predict before surgery whether a patient will be able to walk independently after lower limb amputation ..$^{5,8}$ Several pre-operative ${ }^{9-12}$ and postoperative factors ${ }^{13-22}$ have been associated with the likelihood of being able to walk with a prosthetic limb, but there are no validated methods of predicting this before amputation surgery . 
1 Best practice should ensure that patients are informed in detail before surgery about what

2 type of prosthesis may be suitable, and that they are counselled about their likely 3 prognosis. ${ }^{23}$ This can help manage expectations as well as plan for environmental changes at

4 home or at work, returning to driving and attending social activities. ${ }^{6}$ However, these

5 discussions do not always occur, partly because of the urgent nature of many lower limb

6 amputations. $^{7}$ When pre-amputation discussions do occur there is evidence that patients'

7 expectations of being able to walk independently with a prosthetic limb are often unrealistic

$8{ }^{24}$ and this is borne out by our own clinical experience. This may relate to the prominent

9 media profile of some amputees including war veterans and disabled athletes. Alternatively,

10 advice from surgeons that patients will be suitable for prosthetic rehabilitation after

11 amputation may be over-optimistic, based on a lack of knowledge or available evidence in

12 predicting longer term outcome in different patient groups, or a reluctance to emphasise

13 negative outcomes before surgery.

14 Therefore the aims of this study were to identify pre-operative factors associated with the

15 ability to walk with a prosthetic limb after major lower limb amputation. These would 16 inform the development of a predictive assessment tool that could be used to predict the

17 likelihood of walking with a prosthesis after surgery. 
We conducted a service review of mobility outcomes of all patients $(n=350)$ referred for prosthetic rehabilitation after trans-tibial and trans-femoral amputation between $1^{\text {st }}$ April

$52000-31$ st March 2008 in the tertiary referral vascular and orthopaedic unit at University

6 Hospitals of Leicester NHS Trust. Research ethics committee was not required as this study

7 was a retrospective analysis of routinely collected clinical data. Data were recorded as part

8 of routine care during $2000-2008$ by clinicians from the prosthetic rehabilitation service.

9 The use of anonymised patient information was approved by the institutional review board and individual patient consent was not required Functional outcome was determined using the NHS prosthetic activity coding classification in use at the time (AOL- non limb user, A1Llimited household/cosmetic user, $\mathrm{A} 2 \mathrm{~L}$ - limited community/household user, $\mathrm{A} 3 \mathrm{~L}$ - active adult, A4L - very active adult or athlete)..$^{25}$ Variables included sex, age, body mass index, medical co-morbidities, cause of amputation, level of amputation and impaired cognitive capacity. This creation dataset was limited to those variables collected as part of routine care.

\section{Selection of variables}

Data were entered into an SPSS for Windows version 22 (IBM, Armonk, NY, USA) spreadsheet for analysis. Univariate binary logistic regression analysis of the creation dataset was used to identify potential variables that were predictive of the level of function (ability to walk with prosthetic limb) after amputation. Our primary aim was to identify the likelihood of walking independently with a prosthetic limb. A successful functional outcome 
1 grade at 12 months were deemed to have an unsuccessful rehabilitation outcome. All

2 potential predictors that had an odds ratio $>1$, and a $p$-value $<0.1$ were analysed using

3 multinomial logistic regression analysis, with walking after amputation as the dependent

$4 \quad$ variable, and independent predictors as covariates.

5

6 Development of the BLARt scoring system

7 Following consensus discussion amongst the research team based on regression analysis of

8 the significant variables identified from the creation dataset and previously published

9 literature, 4, 6, 9, 11, 12, 16, 23, 26-37 eight preoperative variables were identified as potentially

10 affecting the success of rehabilitation and having a significant impact on ability to mobilise

11 independently after amputation. The eight variables were:

1: Age. The elderly are more likely to be frail with less strength and can find learning new skills more difficult. ${ }^{12,23,27-29}$

2: Sex. There is conflicting evidence regarding the effect of sex on mobility outcomes. ${ }^{5}$ The creation dataset and previous studies ${ }^{19}, 38$ have shown that women are less successful in rehabilitation.

3: Body mass index (BMI). BMI has an impact on the effective fitting and functioning of a prosthesis. ${ }^{30}$ Obesity can indicate a lower level of fitness and can make socket fitting challenging. Low BMI can also be associated with frailty, lack of physical fitness and affect the socket comfort because of bony prominences.

4: Level of amputation. Walking ability is reduced with more proximal amputations, particularly hip disarticulation, and bilateral amputation; trans-tibial amputees are much 
1 more likely than trans-femoral or through-knee amputees to achieve a functional level of

2 A2L or greater. $4,26,27,29$

3 5: Indication for amputation. Patients undergoing amputation for vascular disease have

4 poorer mobility related outcomes than amputees related to trauma. 4, 6, 23, 27, 31-33

5 6: Mobility before amputation. Patients who are unable to walk independently before

6 surgery, especially those that are wheelchair bound are less likely to walk independently

7 after amputation. This relates to contractures from wheelchair use, compromised balance

8 and muscle strength. ${ }^{9,28}$

9 7: Cognitive impairment. Impaired cognitive function and dementia can affect rehabilitation outcomes. ${ }^{9,16,34}$

8: Special risks

a. Co-existing systemic disease. Systemic co-morbidities including diabetes mellitus,

We defined ischaemic heart disease as current angina or previous myocardial infarction (within 6 months). Severe respiratory disease was defined as COPD causing shortness of breath at rest or requiring home oxygen therapy. Cognitive impairment included overt confusion, with 'limited carry over' being the inability of patients to retain and repeat verbal information shortly after it had been discussed. These variables were included in the BLARt (Blatchford Allman Russell tool) score (Table 1). 
Insert Table 1 about here.

2

\section{Validation of the dataset}

4 The study population for the validation dataset comprised all patients referred after lower

5 limb amputation to the rehabilitation service in Leicester during 2010-2013 and the

6 Northern General Hospital, Sheffield during 2012-2013. The level of functional rehabilitation

7 for the validation dataset was recorded 12 months after surgery using the SIGAM scoring

8 system ( $\mathrm{A}$ - non limb user, B - Therapeutic, wears only for transfers, C - Limited/Restricted,

9 walks up to $50 \mathrm{~m}$, D- Impaired, walks $50 \mathrm{~m}$ or more with walking aid, E- Independent, walks

$1050 \mathrm{~m}$ or more without walking aid, F - Normal/Near normal walking). ${ }^{39}$ The SIGAM

11 classification was used (instead of the AOL activity code used for the creation dataset) because of a change in the NHS Trust requirements for data recording. For the purposes of analysis, prosthetic mobility outcomes were grouped into 2 categories representing a functional or non-functional disability mobility outcome using the SIGAM scale. Nonfunctional mobility outcomes were defined as patients who had died or had a SIGAM grade A (non-limb user) or B (wearing prosthesis only for transfer, unable to walk independently). Functional outcomes were classed as SIGAM grade $\mathrm{C}$ or above. This division into binary outcomes compares closely to the activity grades ( $\mathrm{AOL}$ and $\mathrm{A} 1 \mathrm{~L} ;$ or $\mathrm{A} 2 \mathrm{~L}$ and greater).

\section{Statistical analysis}

Univariate binary logistic regression analysis of the creation dataset was used to identify potential variables that were predictive of functional outcome after amputation. All potential predictors that had an odds ratio $>1$, and a $p$-value $<0.1$ were analysed using 
1 multinomial stepwise forward logistic regression analysis. Variables associated with poor

2 rehabilitation mobility (odds ratio $>1$ on binary regression analysis of the creation dataset, $p$

3 value $<0.1$ ) and those identified from published studies were included in the scoring system,

4 as were variables statistically significant on multinomial analysis. Multinomial regression

5 analysis used outcome after amputation as the dependent variable, and independent

6 predictors as covariates. Since our intention was to develop a system that could predict

7 acceptable outcome at 12 months, outcome was primarily divided into functional (SIGAM

8 grade $\mathrm{C}$ or greater) or non-functional (dead, or SIGAM grade A or B). We also compared

9 outcomes according to good walking function (SIGAM grade E or F) and poor function

10 (SIGAM grade D or lower). The performance of the score, calibration and goodness of fit to

11 the validation dataset was determined by calculating the Hosmer-Lemeshow statistic and

12 Nalgekirke $\mathrm{R}^{2}$ value. Data are presented as $\operatorname{Exp}(\mathrm{B})$ Odds ratios with $95 \%$ confidence intervals, where Exp (B) represents the ratio-change in the odds of the event of interest for

14 a one-unit change in the predictor. Receiver operating characteristic (ROC) curves were constructed and area-under-the ROC curve (AUROC) with SE and 95\% confidence intervals to assess sensitivity and discrimination. Specificity and sensitivity of the BLARt score for predicting functional walking outcomes (defined by SIGAM grade) were calculated for the overall score and at key threshold values. Sensitivity was calculated as the proportion of patients correctly predicted by a high BLARt score as having a non- or poor functional walking outcome) and specificity was calculated as the proportion of patients correctly predicted by a low BLARt score as having a good functional walking outcome. 
RESULTS

3

4

\section{Creation dataset}

Of 350 patients included in the creation dataset, functional outcome data was not recorded for 12 patients so data from 338 patients were analysed (Table 2). The characteristics of the

patient groups are indicated in Tables 2 and 3. Mortality at 12 months was $18.6 \%$.

Insert tables 2 \& 3 about here.

Factors independently associated with a poor functional outcome ( $\mathrm{OOL}$ or $\mathrm{A} 1 \mathrm{~L}$ ) on univariate analysis were trans-femoral amputation, age $>70$ years, male sex, vascular aetiology, renal failure requiring dialysis, diabetes and prior stroke (Table 4) and these were entered into the multinomial analysis.

Insert table 4 about here.

Ischaemic heart disease, obesity, respiratory disease, contralateral limb problems, cognitive dysfunction were not associated with mobility outcome but absolute numbers of patients with these pathologies were low. On multinomial analysis, age, sex, trans-femoral amputation, vascular aetiology and renal failure were independent predictors of nonfunctional mobility outcome (Table 5).

Insert table 5 about here.

\section{Validation dataset and BLARt scoring system development}

One hundred and ninety nine patients were included in the validation dataset (101 from Leicester, 98 from Sheffield). Patient characteristics in the validation dataset $(n=199)$ were similar to the creation dataset (Tables $6 \& 7$ ), though the presence of diabetes was not recorded. Body mass index was calculated. The proportion of patients undergoing trans- 
1 femoral amputations was lower, and 30 patients underwent bilateral amputations or hip

2 disarticulation. Mortality at 12 months in the validation dataset was $10 \%(n=20)$ but other

3 clinical outcomes were similar. Insert tables 6 \& 7 about here.

4 The BLARt scoring system (Table 1 ) was devised based on these variables, with additional

5 weight given to those significant on multinomial analysis. In addition, some factors

6 considered important by the research and clinical teams but not recorded in the creations

7 dataset (body mass index, pre-amputation mobility) were included. The validation dataset

8 was then used to assess the performance of the BLARt score. Using the Hosmer and

9 Lemeshow Test, the BLARt score showed good concordance between predicted and observed functional outcome ( $\chi 2$ value $8.31, p=0.403$ ). Table 8 summarises the correlation between BLARt score and functional outcome.

Insert table 8 about here.

No patient with a BLARt score $\geq 13$ was able to walk independently with a prosthesis (SIGAM

$\mathrm{E}$ or F) and only 6 patients with a BLARt score $\geq 17$ were able to walk independently with a prosthesis for any distance (SIGAM C or greater). The overall sensitivity of the BLARt score for predicting poor functional outcome (SIGAM D or below) was $95.5 \%$ and the specificity was $77.2 \%$; positive and negative predictive values were $97.2 \%$ and $45.5 \%$ respectively. Using a threshold of BLARt score $\geq 13$ or less gave $100 \%$ sensitivity and $66.7 \%$ specificity for poor functional outcome (SIGAM D or below). A threshold of BLARt score $\geq 17$ identified non-functional outcome (SIGAM B or below) with a sensitivity of $93.4 \%$ and a specificity of $75.9 \%$

The ROC curve for non-functional outcome (Figure 1) confirms the predictive ability of the BLARt score. The AUC is 0.914 (SE 0.2), 95\% confidence intervals 0.87-0.95. AUROC for poor functional outcome was 0.941 (SE 0.017) (95\% Cl 0.91-0.97). 


\section{Insert Figure 1 about here.}

2

3

Page | 13 


\section{DISCUSSION}

In this study we found that patients with a BLARt score of $\geq 13$ did not achieve a good functional outcome (SIGAM grade E or F) following lower limb amputation and those with a score of $\geq 17$ did not achieve any walking function (SIGAM grade $C$ or greater). The BLARt assessment was highly sensitive in identifying a patient's subsequent ability to walk.

In the creation dataset of 338 patients, those undergoing through-knee or trans-femoral amputation had a $10.5 \%$ chance of achieving good functional outcome ( $A 2 L, A 3 L$ or $A 4 L$ ) compared to $41 \%$ in the trans-tibial amputation group. The poorer outcome after transfemoral amputation is consistent with published data. ${ }^{23,} 38$ In the second cohort of 199 patients used as the validation dataset, a good functional outcome was achieved by $36 \%$ of the through-knee/transfemoral group and $69 \%$ of trans-tibial group. This suggests that rehabilitation outcomes may have improved in the last decade, which probably reflects improvements in rehabilitation services. Other strong predictors of poor functional outcome were renal failure, female sex and amputation for peripheral vascular disease, again consistent with previous data. The effects of renal failure may be because of reduced life expectancy $^{40-42}$ and the multiple co-morbidities associated with end-stage renal disease ${ }^{43 .}$ In our experience, inconsistency in physical wellbeing on a day-to-day basis is a major limitation in the rehabilitation process, and this occurs in patients with renal failure. Our data demonstrated that older female patients with peripheral vascular disease were less likely to walk independently after amputation. This may be related to a number of reasons 
1 such as the severity of the underlying vascular disease, frailty, social, demographic and

2 psychological factors associated with adjustment to amputation. ${ }^{44}$

3 Functional outcomes were better when amputation was performed in younger patients for

4 traumatic or orthopaedic injuries rather than peripheral vascular disease. The BLARt score

5 was less good at predicting a 'good' functional outcome (walking independently). One

6 explanation is that the BLARt score measures pre-amputation factors and does not consider

7 post-amputation factors, which are likely to have an influence on outcome. There are many

8 unpredictable post-operative factors that can affect successful rehabilitation. These include

9 failure of, or poor wound healing, infection requiring revision surgery, contractures, and

10 acute post-operative events such as infectious, respiratory or cardiovascular complications.

11 Patients who undergo amputation have to make many psychological and social adjustments

12 and these influence outcomes. Patients who are discharged home may feel isolated

13 following a prolonged period of hospitalisation. They may withdraw socially and may not perform their physiotherapy exercises as much as patients who go to a community rehabilitation facility where more regular input and help to deal with complications is often available. Motivation is an important determinant of rehabilitation. ${ }^{11}$ Factors affecting motivation and compliance include mood changes, anxiety, changes in body image and selfesteem. Social support issues, feelings of helplessness and coping with the physical adaptations required can all influence rehabilitation outcomes. ${ }^{17,} 27$ Many of these are difficult to predict before amputation surgery and were not included in the BLARt tool. Hence the utility of the BLARt is to predict those patients who are unlikely to rehabilitate successfully rather than those who will. 


\section{Implications for practice}

2 The BLARt score is a relatively simple tool that will allow risk stratification for the purposes

3 of informed consent. It will provide an estimate of prognosis that can guide pre-operative

4 information giving and communication. It may allow better management of the

5 expectations of patients and their carers, during the informed consent process.

6 It is a simple, reproducible tool that can be easily incorporated into every day clinical

7 practice. The BLARt score can be completed by any member of the clinical team and does

8 not require a specialist practitioner.

9

10 


\section{Limitations of the current study}

3 The creation dataset comprised routine collected data which did not include variables such

4 as categorised body mass index, pre-amputation mobility levels and classification of

5 cognitive impairment. Hip disarticulation, and bilateral amputations were also not classified

6 separately. However, the study team considered these to be vital factors which affect the

7 success of rehabilitation and therefore, following consensus decision, they were included

8 and weighted in the formulation of the BLARt score. There were very few through-knee

9 amputations in our datasets and so these have been grouped together with the transfemoral group. We feel this is logical as in our experience the absence of a knee joint

11 (as in transfemoral or through knee amputations) is a major limiting factor in rehabilitation

The incidence of diabetes was included in the creation dataset analysis and was a significant co morbidity ( $n=152,45 \%$ of patients undergoing amputation). However, we omitted diabetes from the BLARt assessment because whilst it is an underlying risk factor for peripheral vascular disease and amputation it does not necessarily impact on rehabilitation. In attempting to distinguish between patients with unlimited walking distance before surgery and those able to walk a limited distance unaided, we used ability to walk 3 miles as a surrogate for unlimited walking, which approximates to a SIGAM mobility grade $F$ (normal/near normal walking) and NHS prosthetic activity code A3L. We realise that this definition is to some extent subjective, but our intention was to predict broadly whether a patient would achieve any walking function (SIGAM grade $\mathrm{C}$ or greater) or independent mobility (SIGAM grade E or F). To achieve this it is more important to distinguish levels of immobility rather of extended mobility before surgery. It is possible that a different 
1 definition of unlimited or normal walking might have improved performance of the BLARt,

2 but we believe this is unlikely, and grouped SIGAM grades $\mathrm{E}$ and $\mathrm{F}$ together for analysis.

3 We recognise that there are several other post-operative factors that can impact on the

4 success of prosthetic ambulation and good functional outcome. Wound healing, stump

5 characteristics (affecting prosthetic fitting), phantom limb pain, amputation stump pain and

6 psychosocial issues $37,46,47$ can all prolong the rehabilitation process. However these cannot

7 be predicted before surgery and therefore are not accounted for in the BLARt assessment.

8

\section{$9 \quad$ Further studies}

10 Further studies are required and planned to use the BLARt assessment in a larger population

11 across several centres nationwide, in order to validate the tool in a larger patient group. It

12 is anticipated that this assessment could ultimately be incorporated into routine clinical

13 practice to guide and inform patients about their potential mobility outcomes after lower

$14 \operatorname{limb}$ amputation.

15 


\section{CONCLUSIONS}

3 We have developed a novel scoring system to predict the likelihood of walking after lower

4 limb amputation. The BLARt score offers a consistent pre-operative assessment based on

5 objective evaluation of underlying clinical variables and their influence on rehabilitation

6 after lower limb amputation. It could provide patients and clinicians with a more realistic

7 prediction of the chances of walking after surgery, and assist in setting realistic objectives

8 and expectations.

\section{Acknowledgements}

Alison Stenson, Blatchford Clinical Services, Sheffield - Data Collection.

Declaration of Interest

12 The authors report no conflicts of interest.

\section{REFERENCES}

14 [1] NHS Choices [Internet]. [cited 2015 Jan 6]; Available from:

15 http://www.nhs.uk/conditions/amputation/Pages/Introduction.aspx

[2] Esquenazi A. Amputation rehabilitation and prosthetic restoration. From surgery to community reintegration. Disability and Rehabilitation 2004; 26: 831-836

[3] Marshall C, Stansby G. Amputation and Rehabilitation. Surgery (Oxford): Vascular

[4] Jordan RW, Marks A, Higman D. The cost of major lower limb amputation: a 12 year experience. Prosthetics and Orthotics International 2012; 36: 430-434

[5] Sansam K, Neumann V, O'Connor R, Bhakta B. Predicting walking ability after lower limb amputation: A Systematic review of the literature. Journal of Rehabilitation Medicine 2009; 41: 593-603

[6] Cumming J, Barr S, Howe TE. Prosthetic rehabilitation for older dysvascular people after a unilateral transfemoral amputation. Cochrane Database of Systematic Reviews 2006; 4 
[7] Quality improvement framework for amputation guidance [Internet]. VSGBI, London

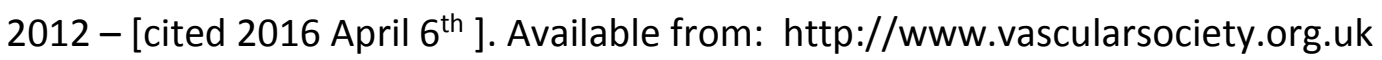

[8] Robinson V, Sansam K, Hirst L, Neumann V. Major lower limb amputation - what, why and how to achieve the best results. Amputations and Prosthetics 2010; 24: 276-285

[9] Taylor SM, Kalbaugh CA, Blackhurst DW, Hamontree SE, Cull DL, Messich HS, Robertson RT, Langan EM et al. Preoperative clinical factors predict postoperative functional outcomes after major lower limb amputation: An Analysis of 553 consecutive patients. Journal of Vascular Surgery 2005; 42: 227-35

[10] Taylor SM, Kalbaugh CA, Cass AL, Buzzell NM, Daly CA et al. Successful outcome after below knee amputation: An objective definition and influence of clinical variables. American Surgeon 2008; 74: 607-612

[11] Hamamura S, Chin T, Kuroda R, Akisue T, Iguchi T, Kohno H et al. Factors affecting prosthetic rehabilitation outcomes in amputees of age 60 years and over. The Journal of International Medical Research 2009; 37: 1921-1927

[12] Munin MC, Espejo-De Guzman MC, Boninger ML, Fitzgerald SG, Penrod LE, Singh J. Predictive factors for successful early prosthetic ambulation among lower-limb amputees. Journal of Rehabilitation Research and Development 2001; 38; 4: 379-384

[13] Raya MA, Gailey RS, Fiebert IM, Roach KE. Impairment variables predicting activity limitation in individuals with lower limb amputation. Prosthetics and Orthotics International 2010; 34: 73-84

[14] Suckow BD, Goodney PP, Cambria RA, Bertges DJ et al. Predicting Functional Status Following Amputation After Lower Extremity Bypass. Annuals of Vascular Surgery 2012; 26: 67-78

[15] Callaghan B, Condie E, Johnston M. Using the common sense self- regulation model to determine psychological predictors of prosthetic use and activity limitations in lower limb amputees. Prosthetics and Orthotics International 2008; 32: 324-336

[16] O’Neill BF, Evans JJ. Memory and executive function predict mobility rehabilitation outcome after lower-limb amputation. Disability and Rehabilitation 2009; 31: 1083-1091

[17] Coffey L, Gallagher P, Desmond D. A Prospective study of the importance of life goal characteristics and goal adjustment capacities in longer term psychosocial adjustment to lower limb amputation. Clinical Rehabilitation 2014; 28: 196-205

[18] Schoppen T, Boonstra A, Groothoff JW, de Vries J, Goeken L, Eisma W. Physical, mental and social predictors of functional outcome in unilateral lower-limb amputees. Archives of Physical Medicine and Rehabilitation 2003; 84: 803-811 
[19] Sansam K, O'Connor RJ, Neumann V, Bhakta B. Can simple clinical tests predict walking ability after prosthetic rehabilitation? Journal of Rehabilitation Medicine 2012; 44: 968-974

[20] Glemme M, Ramstrand N, Crafoord J, Nygren L. Preoperative characteristics and functional outcomes of lower limb amputees treated at Southern Alvsborg Hospital, Sweden. Prosthetics and Orthotics International 2012; 37: 298-304

[21] Sauter C, Pezzin LE, Dillingham TR. Functional Outcomes of Persons Undergoing Dysvascular Lower Extremity Amputations. American Journal of Physical Medicine and Rehabilitation 2013; 92: 287-296

[22] Campbell WB, Ridler BMF. Predicting the Use of Prostheses by Vascular Amputees. European Journal of Vascular Endovascular Surgery 1996; 12: 343-345

[23] Davies B, Datta D. Mobility outcome after unilateral lower limb amputation. Prosthetics and Orthotics International 2003; 27: 186-190

[24] Murray CD, Forshaw MJ. Look and feel your best : respresentations of artificial limb users in prosthetic company advertisements. Disability and Rehabilitation 2014; 36, 2, 170 176.

[25] Douglas Bader Foundation [Internet]. Disability Mobility Grades [cited 2015 Jan 6]; Available from: http://www.douglasbaderfoundation.com/bill/information/amputationprosthetics/activity-levels

[26] Leung EC, Rush PJ, Devlin M. Predicting prosthetic rehabilitation outcome in lower limb amputee patients with the functional independence measure. Archives of Physical Medicine \& Rehabilitation 1996; 77: 605-608

[27] Geertzen JH, Bosmans JC, Van De Schans CP, Dijkstra PU. Claimed walking distance of lower limb amputees. Disability and Rehabilitation 2005; 27: 101-104

[28] Johannesson A, Larsson G, Ramstrand N, Lauge-Pedersen H, Wagner P, Atroshi I. Outcomes of a standardized surgical and rehabilitation program in transtibial amputation for peripheral vascular disease. American Journal of Physical Medicine and Rehabilitation 2010; 89; 4: 293-303

[29] Dowling M, Kelly M. Patient rehabilitation following lower limb amputation. Nursing Standard 2008; 22; 49: 35-40

[30] Haboubi N HJ, Heelis M, Woodruff R, Al-Khawaja I. The effect of body weight and age on frequency of repairs in lower-limb prostheses. Journal of Rehabilitation Research and Development 2001; 38; 4: 375-377

[31] Volpicelli LJ, Chambers RB, Wagner JFW. Ambulation levels of bilateral lower-extremity amputees. Analysis of one hundred and 3 cases. Journal of Bone and Joint Surgery 1983; 65: $599-605$ 
[32] Ng EK, Berbrayer D, Hunter GA. Transtibial amputation: preoperative vascular assessment and functional outcome. Journal of Prosthetics and Orthotics 1996; 8: 123-129

[33] Burger $\mathrm{H}$, Marineck $\mathrm{C}$. Functional testing of elderly subjects after lower limb amputation. Prosthetics and Orthotics International 2001; 25: 102-107

[34] Callaghan B, Condie E, Johnston M. Prosthetics and Orthotics International 2008; 32: 324-336

[35] Johnson VJ, Konziela S, Gottschalk F. Pre and post-amputation mobility of transtibial amputees: correlation to medical problems, age, and mortality. Prosthetics and Orthotics International 1995; 19: 159-64.

[36] Hordacre B, Birks V, Quinn S, Barr C, Patritti BL, Crotty M. Physiotherapy rehabilitation for individuals with lower limb amputation: A 15 year clinical series. Physiotherapy Research International 2013; 18: 70-80

[37] Schoppen T, Boonstra A, Groothoff JW et al. Physical, mental and social predictors of functional outcome in unilateral lower-limb amputees. Archives of Physical Medicine and Rehabilitation 2003; 84: 803-811

[38] Scott H, Patel R, Hebenton J. 2012. A survey of the lower Limb Amputee Population in Scotland 2010. Scottish Physiotherapy Amputee Research Group. www.csp.org.uk/sites/files/csp/secure/sparg_report_2010_final1.pdf. Accessed 2014 Oct 27

[39] Ryall NH, Eyres SB, Neumann VC, Bhakta BB, Tennant BB. The SIGAM mobility grades: a new population specific measure for lower limb amputees. Disability and Rehabilitation 2003; $25: 15,833-844$

[40] Eggers PW, Gohdes D, Pugh J. Nontraumatic lower extremity amputations in the Medicare end-stage renal disease population. Kidney International 1999; 56: 1524-1533

[41] Lavery LA, Hunt NA, Ndip A, Lavery DC, Van Houtum W, Boulton AJM. Impact of chronic kidney disease on survival after amputation in individuals with diabetes. Diabetes Care 2010; 33: 2365-2369

[42] Margolis DJ, Hofstad O, Feldman HI. Association between renal failure and foot ulcer or lower extremity amputation in patients with diabetes. Diabetes Care 2008; 31: 1331-1336

[43] Prichard SS. Comorbidities and their impact on outcome in patients with end stage renal disease. Kidney International 2000; 57: 74: S-100-S-104

[44] Hawamdeh ZM, Othman YS, Ibrahim Al. Assessment of anxiety and depression after lower limb amputation in Jordanian patients. Neuropsychiatric Disease and Treatment 2008; 4: 627-633 
2 [45] Blatchford Clinical Services, Blatchford Group 2014. (unpublished data)

3 http://www.blatchford.co.uk/clinics/leicester/

4 [46] Geertzen J, Van der Linde H, Rosenbrand K et al. Dutch evidence-based guidelines for 5 amputation and prosthetics of the lower extremity. Part 2. Prosthetics and Orthotics

6 International 2014; 24: 1-11

7 [47] Coffey L, Gallagher P, Desmond D. A prospective study of the importance of life goal 8 characteristics and goal adjustment capacities in longer term psychosocial adjustment to 9 lower limb amputation. Clinical Rehabilitation 2014; 28: 196-205 
Table 1: BLARt Assessment Tool

\begin{tabular}{|l|l|l|l|l|}
\hline Sex & Score & & Special Risks & Score \\
\hline Male & $\mathbf{0}$ & & Severe respiratory disease & $\mathbf{5}$ \\
\hline Female & $\mathbf{1}$ & & Renal failure requiring dialysis & $\mathbf{4}$ \\
\hline & & & Stroke & $\mathbf{3}$ \\
\hline Age in years & & & Recent MI / Angina $^{4}$ & $\mathbf{2}$ \\
\hline $14-49$ & $\mathbf{0}$ & & Contralateral Limb Problem & $\mathbf{2}-\mathbf{4}$ \\
\hline $50-64$ & $\mathbf{1}$ & & & \\
\hline $65-74$ & $\mathbf{2}$ & & Indication for Amputation & \\
\hline $75-80$ & $\mathbf{5}$ & & Trauma & $\mathbf{0}$ \\
\hline $80+$ & $\mathbf{6}$ & & Congenital & $\mathbf{0}$ \\
\hline & & & Cancer & $\mathbf{1}$ \\
\hline BMI & & & Orthopaedic & $\mathbf{2}$ \\
\hline $18.5-24.9$ (Average) & $\mathbf{0}$ & & Vascular & $\mathbf{3}$ \\
\hline $25-29.9$ (Above Average) & $\mathbf{1}$ & & & \\
\hline $30+($ Obese) & $\mathbf{3}$ & & Level of Amputation & \\
\hline 18.5 or less (Below Average) & $\mathbf{2}$ & & Transfemoral /Through Knee & $\mathbf{3}$ \\
\hline & & & Transtibial & $\mathbf{1}$ \\
\hline Mobility Before Amputation & & & Hip Disarticulation & $\mathbf{5}$ \\
\hline Wheelchair bound $\geq 12$ months & $\mathbf{5}$ & & Bilateral & $\mathbf{4}$ \\
\hline Wheelchair bound $<12$ months & $\mathbf{4}$ & & & \\
\hline Indoor mobility with aids & $\mathbf{3}$ & & Cognitive Impairment \\
\hline Outdoor mobility with aids & $\mathbf{2}$ & & Confused & \\
\hline Unaided outdoor mobility & $\mathbf{1}$ & & Limited Carry Over & $\mathbf{5}$ \\
\hline Able to walk $\geq 3$ miles & $\mathbf{0}$ & & Alert / Aware & $\mathbf{3}$ \\
\hline & & & & $\mathbf{0}$ \\
\hline & & & Total Score: & \\
\hline
\end{tabular}

${ }^{1}$ Contralateral Limb Problems - score varies depending on the degree of disability, for example:

Score 2 - Underlying claudication (can weight bear), leg ulcers or knee replacement.

Score 3 - Toe / partial foot amputation (difficulty weight bearing due to neuropathy or balance issues).

Score 4 - Previous amputation or severe disease to limb (not able to weight bear or stand).

${ }^{2}$ Severe Respiratory Disease - defined as a history of COPD, home oxygen therapy or shortness of breath at rest.

${ }^{3}$ Stroke - defined as a history of stroke with residual motor deficit. Patients who had contralateral lower limb weakness also score on the contralateral limb problems scale.

${ }^{4}$ Recent MI / Angina - MI within the last 6 months or ongoing angina.

${ }^{5}$ Level of amputation- through-knee and transfemoral amputations are grouped together

Score 4 - bilateral transtibial amputation

Score 5 - transtibial and contralateral through-knee or transfemoral amputation

Score 6 - bilateral transfemoral or through-knee amputation

${ }^{6}$ Cognitive Impairment is defined as the inability of patients to retain information shortly after it had been discussed, such as physiotherapy exercises and basic instructions. It was categorised as:

Score 5 - Confused (unable to understand and retain information).

Score 3 - Limited Carry Over (able to understand but not retain information).

Score 0 - Alert/ Aware (able to understand and retain information). 
2

\begin{tabular}{|c|c|c|}
\hline & $\begin{array}{c}\text { Transfemoral/through- } \\
\text { knee amputations ( } n=152)\end{array}$ & $\begin{array}{c}\text { Transtibial amputations } \\
\qquad(n=186)\end{array}$ \\
\hline Age (years) & $69.5(15-95)$ & $65(15-92)$ \\
\hline Male/Female & $109(72 \%) / 43(28 \%)$ & $144(77 \%) / 42(23 \%)$ \\
\hline \multicolumn{3}{|l|}{ Indication for Amputation } \\
\hline $\operatorname{Vascular}(n=282)$ & 127 (84\%) & 155 (83\%) \\
\hline $\begin{array}{l}\text { Orthopaedic/Trauma/Congenital } \\
(n=45)\end{array}$ & $19(12 \%)$ & $26(14 \%)$ \\
\hline Cancer $(n=11)$ & $6(4 \%)$ & $5(3 \%)$ \\
\hline \multicolumn{3}{|l|}{ Coexisting Morbidity $^{1}$} \\
\hline Diabetes $(n=152)$ & $52(34 \%)$ & $100(54 \%)$ \\
\hline Ischaemic heart disease $(n=81)$ & $32(21 \%)$ & $49(26 \%)$ \\
\hline Stroke $(n=44)$ & $16(11 \%)$ & $28(15 \%)$ \\
\hline Renal Failure ( $n=33)$ & $13(9 \%)$ & $20(11 \%)$ \\
\hline Severe respiratory Disease $(n=32)$ & $12(8 \%)$ & $20(11 \%)$ \\
\hline Contralateral limb problem $(n=33)$ & 0 & $33(18 \%)$ \\
\hline Cognitive impairment $(n=10)$ & 0 & $10(5 \%)$ \\
\hline Obesity $(n=7)$ & 0 & $7(4 \%)$ \\
\hline Congestive heart failure $(n=6)$ & 0 & $6(3 \%)$ \\
\hline \multicolumn{3}{|l|}{$\begin{array}{l}\text { Activity Level Achieved at } 12 \\
\text { months }^{2}\end{array}$} \\
\hline $\mathrm{AOL}(n=110)$ & 80 (52\%) & 30 (16\%) \\
\hline A1L $(n=73)$ & $24(16 \%)$ & $49(26.5 \%)$ \\
\hline $\mathrm{A} 2 \mathrm{~L}(n=62)$ & $9(6 \%)$ & $53(28.5 \%)$ \\
\hline $\mathrm{A} 3 \mathrm{~L}(n=26)$ & $7(5 \%)$ & $19(10 \%)$ \\
\hline A4L $(n=4)$ & 0 & $4(2 \%)$ \\
\hline Died $(n=63)$ & $32(21 \%)$ & $31(17 \%)$ \\
\hline
\end{tabular}

${ }^{1}$ Many patients had more than 1 coexisting morbidity hence column totals $=>100 \%$. Contralateral limb problem was defined as in Table 1 . Obesity was defined as BMl>30 $\mathrm{kg} \mathrm{m}^{-2}$.

${ }^{2} \mathrm{NHS}$ activity coding classification - see Figure 1 
Table 3: Comparison of Patient Characteristics according to Level of Functional Rehabilitation at

412 months - Creation dataset $(n=338)$

5

\begin{tabular}{|c|c|c|c|}
\hline Level of Functional Rehabilitation & $\begin{array}{c}\text { Functional } \\
\mathrm{A} 2 \mathrm{~L}, \mathrm{~A} 3 \mathrm{~L}+\mathrm{A} 4 \mathrm{~L} \\
(n=92)\end{array}$ & $\begin{array}{c}\text { Non-Functional } \\
\text { A0L + A1L } \\
(n=183)\end{array}$ & Died $(n=63)$ \\
\hline \multicolumn{4}{|l|}{ Age (years) } \\
\hline $14-49$ & $34(37 \%)$ & $6(3 \%)$ & $2(3.1 \%)$ \\
\hline $50-64$ & $24(26 \%)$ & $57(31 \%)$ & 9 (14.3\%) \\
\hline $65-74$ & $16(17 \%)$ & $52(29 \%)$ & $16(25.5 \%)$ \\
\hline $75-80$ & $12(13 \%)$ & $35(19 \%)$ & $19(30.1 \%)$ \\
\hline $81+$ & $6(7 \%)$ & $33(18 \%)$ & $17(27 \%)$ \\
\hline Male: Female & $84: 8$ & $124: 59$ & $45: 18$ \\
\hline \multicolumn{4}{|l|}{ Indication for Amputation } \\
\hline Vascular & $58(63 \%)$ & $166(91 \%)$ & $58(92 \%)$ \\
\hline Orthopaedic/Trauma/Congenital & $31(34 \%)$ & $11(6 \%)$ & $3(5 \%)$ \\
\hline Cancer & $3(3 \%)$ & $6(3 \%)$ & $2(3 \%)$ \\
\hline \multicolumn{4}{|l|}{ Coexisting Morbidity } \\
\hline Diabetes & $37(40 \%)$ & $80(44 \%)$ & $35(56 \%)$ \\
\hline Ischaemic heart disease & $18(19 \%)$ & $43(23 \%)$ & $20(32 \%)$ \\
\hline Stroke & $7(8 \%)$ & $28(15 \%)$ & $9(14 \%)$ \\
\hline Renal failure & $3(3 \%)$ & $17(9 \%)$ & $13(21 \%)$ \\
\hline Severe respiratory disease & $8(9 \%)$ & $19(10 \%)$ & $5(8 \%)$ \\
\hline \multicolumn{4}{|l|}{ Obesity } \\
\hline Obese & $3(3 \%)$ & $4(2 \%)$ & $0(0 \%)$ \\
\hline Not obese & $89(97 \%)$ & $179(98 \%)$ & $63(100 \%)$ \\
\hline Contralateral Limb Problem & $10(11 \%)$ & $16(9 \%)$ & $7(11 \%)$ \\
\hline \multicolumn{4}{|l|}{ Cognitive Impairment } \\
\hline Confused & $2(2 \%)$ & $3(2 \%)$ & $5(8 \%)$ \\
\hline Alert/aware & $90(98 \%)$ & $180(98 \%)$ & $58(92 \%)$ \\
\hline \multicolumn{4}{|l|}{ Level of Amputation } \\
\hline Transfemoral /through knee & $16(17 \%)$ & $104(57 \%)$ & 32 (51\%) \\
\hline Transtibial & $76(83 \%)$ & $79(43 \%)$ & 31 (49\%) \\
\hline
\end{tabular}

6 Percentages refer to column totals. Many patients had more than 1 coexisting morbidity hence some column totals $=>$

$7 \quad 100 \%$. 
2 Table 4: Results of univariate binary logistic regression of the creation dataset according to

3 mobility grade AOL or A1L $(n=338)$

\begin{tabular}{|l|l|l|}
\hline Variable & $\begin{array}{l}\text { Odds ratio (95\% confidence } \\
\text { interval) }\end{array}$ & Significance (p value) \\
\hline $\begin{array}{l}\text { Level (transfemoral or through-knee } \\
\text { amputation) }\end{array}$ & $6.01(3.36-11.1)$ & $<0.001$ \\
\hline Age $>70$ years & $5.70(2.80-11.63)$ & $<0.001$ \\
\hline Male Sex & $4.88(1.51-27.2)$ & $<0.001$ \\
\hline Vascular indication for amputation & $1.84(1.36-2.47)$ & 0.004 \\
\hline Renal failure & $4.19(1.25-14.11)$ & 0.02 \\
\hline Diabetes & $1.96(0.93-4.14)$ & 0.07 \\
\hline Stroke & $1.95(0.85-4.66)$ & 0.10 \\
\hline Ischaemic heart disease & $1.39(0.77-2.50)$ & 0.28 \\
\hline Obesity & $2.00(0.11-2.27)$ & 0.37 \\
\hline Arthritis & $1.46(0.24-1.9)$ & 0.47 \\
\hline Cognitive impairment & $1.54(0.32-7.38)$ & 0.59 \\
\hline Severe respiratory disease & $1.10(0.48-2.56)$ & 0.82 \\
\hline Contralateral limb problem & $1.16(0.39-1.89)$ & 0.86 \\
\hline
\end{tabular}


2 Table 5: Multinomial stepwise forward logistic regression analysis of creation dataset $(n=338)$.

\begin{tabular}{|l|l|l|l|}
\hline Variable & Odds ratio & 95\% confidence interval & $\begin{array}{l}\text { Significance }(\boldsymbol{p} \\
\text { value) }\end{array}$ \\
\hline Age $>75$ years & 2.15 & $1.49-3.13$ & $<0.001$ \\
\hline Sex & 4.60 & $2.79-17.95$ & $<0.001$ \\
\hline Vascular disease & 4.79 & $2.08-11.0$ & $<0.001$ \\
\hline $\begin{array}{l}\text { Level (trans-femoral/through- } \\
\text { knee amputation) }\end{array}$ & 9.46 & $4.49-19.9$ & $<0.001$ \\
\hline Renal failure & 5.7 & $1.53-21.43$ & 0.009 \\
\hline Stroke & 1.67 & $0.62-4.45$ & 0.31 \\
\hline Diabetes & 1.54 & $0.79-3.02$ & 0.21 \\
\hline
\end{tabular}

3

4 
Table 6: Characteristics of Patients in Validation dataset $(n=199)$ who underwent major

3 amputation. Data presented as mean (range) or number (\%).

\begin{tabular}{|c|c|c|c|}
\hline & $\begin{array}{c}\text { Transfemoral/through- } \\
\text { knee amputations } \\
(n=101)\end{array}$ & $\begin{array}{c}\text { Transtibial } \\
\text { Amputations } \\
(n=68)\end{array}$ & $\begin{array}{c}\text { Bilateral or Hip } \\
\text { Disarticulation } \\
\quad(n=30)\end{array}$ \\
\hline Age (years) & $71(38-97)$ & $63(14-92)$ & $66(32-88)$ \\
\hline Male/Female & 60 (59\%)/41 (41\%) & $49(72 \%) / 19(28 \%)$ & $21(70 \%) / 9(30 \%)$ \\
\hline \multicolumn{4}{|l|}{ Indication for Amputation } \\
\hline Vascular & 85 (84\%) & $52(76 \%)$ & 27 (90\%) \\
\hline Orthopaedic/Trauma/Congenital & $14(14 \%)$ & $14(21 \%)$ & $2(6.6 \%)$ \\
\hline Cancer & $2(2 \%)$ & $2(3 \%)$ & $1(3.3 \%)$ \\
\hline \multicolumn{4}{|l|}{ Coexisting Morbidity } \\
\hline IHD & $8(8 \%)$ & $8(12 \%)$ & $1(3.3 \%)$ \\
\hline Stroke & $8(8 \%)$ & $7(10 \%)$ & $3(10 \%)$ \\
\hline Renal Failure & $2(2 \%)$ & $6(9 \%)$ & $3(10 \%)$ \\
\hline Severe respiratory disease & $16.5(17 \%)$ & $7(10 \%)$ & $4(13 \%)$ \\
\hline Diabetes & NR & NR & NR \\
\hline \multicolumn{4}{|l|}{ Body Mass Index (BMI) } \\
\hline < 18.5 (Below Average) & $17(16.5 \%)$ & $5(7 \%)$ & $5(17 \%)$ \\
\hline 18.5 - 24.9 (Average) & $46(46 \%)$ & 37 (54\%) & $13(43 \%)$ \\
\hline 25 - 29.9 (Above Average) & $21(21 \%)$ & $16(24 \%)$ & $9(30 \%)$ \\
\hline >30 (Obese) & $17(16.5 \%)$ & $10(15 \%)$ & $3(10 \%)$ \\
\hline Contralateral Limb Problem & $27(27 \%)$ & $9(13 \%)$ & $7(23 \%)$ \\
\hline \multicolumn{4}{|l|}{ Cognitive Impairment } \\
\hline Confused & $10(10 \%)$ & $3(5 \%)$ & $2(7 \%)$ \\
\hline Alert / Aware & 75 (74\%) & $54(79 \%)$ & $20(66 \%)$ \\
\hline Limited Carry Over & $16(16 \%)$ & $11(16 \%)$ & $8(27 \%)$ \\
\hline \multicolumn{4}{|l|}{$\begin{array}{l}\text { Activity Level Achieved at } 12 \\
\text { months }\end{array}$} \\
\hline SIGAM A & $46(45 \%)$ & $8(12 \%)$ & $20(66 \%)$ \\
\hline SIGAM B & $7(7 \%)$ & $6(9 \%)$ & $2(6 \%)$ \\
\hline SIGAM C & $18(17 \%)$ & $19(26 \%)$ & $5(17 \%)$ \\
\hline SIGAM D & $13(13 \%)$ & $11(16 \%)$ & $2(7 \%)$ \\
\hline SIGAM E & $4(4 \%)$ & $4(6 \%)$ & 0 \\
\hline SIGAM F & $1(1 \%)$ & $13(20 \%)$ & 0 \\
\hline Died & $12(12 \%)$ & $7(11 \%)$ & $1(4 \%)$ \\
\hline \multicolumn{4}{|l|}{ Mobility Before Amputation } \\
\hline Wheelchair bound $\geq 12$ months & $14(14 \%)$ & $4(6 \%)$ & $10(33 \%)$ \\
\hline Wheelchair bound $<12$ months & $10(10 \%)$ & $2(3 \%)$ & $1(3.5 \%)$ \\
\hline Indoor mobility with aids & $34(34 \%)$ & $14(20 \%)$ & $8(27 \%)$ \\
\hline Outdoor mobility with aids & $15(15 \%)$ & $15(22 \%)$ & $6(20 \%)$ \\
\hline Unaided outdoor mobility & $16(16 \%)$ & $17(25 \%)$ & $1(3.5 \%)$ \\
\hline Able to walk $\geq 3$ miles & $12(11 \%)$ & $16(24 \%)$ & $4(13 \%)$ \\
\hline
\end{tabular}



months in validation dataset using the SIGAM scale ${ }^{39}(n=199)$. SIGAM grades C, D \& E were used to define a good functional outcome; non-functional rehabilitation outcome equated to SIGAM grades $A \& B$

\begin{tabular}{|c|c|c|c|}
\hline $\begin{array}{l}\text { Level of Functional } \\
\text { Rehabilitation }\end{array}$ & $\begin{array}{c}\text { Functional } \\
\text { SIGAM C, D, E + F } \\
(n=90)\end{array}$ & $\begin{array}{c}\text { Non-functional } \\
\text { SIGAM A + B } \\
(n=89)\end{array}$ & Died $(n=20)$ \\
\hline \multicolumn{4}{|l|}{ Age (years) } \\
\hline $14-49$ & $20(22 \%)$ & 7 (8\%) & 0 \\
\hline $50-64$ & $26(29 \%)$ & $16(18 \%)$ & $4(20 \%)$ \\
\hline $65-74$ & $23(26 \%)$ & $24(27 \%)$ & $6(30 \%)$ \\
\hline $75-80$ & $13(14 \%)$ & $16(18 \%)$ & $4(20 \%)$ \\
\hline $80+$ & $8(9 \%)$ & $26(29 \%)$ & $6(30 \%)$ \\
\hline Male: Female & 69: 21 & 46: 43 & 15: 5 \\
\hline \multicolumn{4}{|l|}{ Indication for Amputation } \\
\hline Vascular & $66(74 \%)$ & $90(90 \%)$ & $18(90 \%)$ \\
\hline Orthopaedic /Trauma/Congenital & $19(21 \%)$ & $10(10 \%)$ & $2(10 \%)$ \\
\hline Cancer & $5(5 \%)$ & $0(0 \%)$ & 0 \\
\hline \multicolumn{4}{|l|}{ Coexisting Morbidity } \\
\hline IHD & $6(7 \%)$ & $10(11 \%)$ & $2(10 \%)$ \\
\hline Stroke & $5(5 \%)$ & $11(12 \%)$ & $2(10 \%)$ \\
\hline Renal Failure & $1(1 \%)$ & $7(8 \%)$ & $4(20 \%)$ \\
\hline Severe respiratory Disease & $3(3 \%)$ & $20(22 \%)$ & $3(15 \%)$ \\
\hline Diabetes & NR & NR & NR \\
\hline \multicolumn{4}{|l|}{ Body Mass Index (BMI) } \\
\hline 18.5 - 24.9 (Average) & $54(60 \%)$ & $29(33 \%)$ & $13(65 \%)$ \\
\hline 25 - 29.9 (Above Average) & $19(21 \%)$ & $24(27 \%)$ & $3(15 \%)$ \\
\hline $30+($ Obese) & $8(9 \%)$ & $20(22 \%)$ & $2(10 \%)$ \\
\hline 18.5 or less (Below Average) & $9(10 \%)$ & $16(18 \%)$ & $2(10 \%)$ \\
\hline Contralateral limb Problem & $13(14 \%)$ & $33(37 \%)$ & $1(5 \%)$ \\
\hline \multicolumn{4}{|l|}{ Cognitive Impairment } \\
\hline Confused & $1(1 \%)$ & $10(11 \%)$ & $4(20 \%)$ \\
\hline Limited Carry Over & $8(9 \%)$ & $21(24 \%)$ & $6(30 \%)$ \\
\hline Alert/ Aware & $81(90 \%)$ & $58(65 \%)$ & $10(50 \%)$ \\
\hline \multicolumn{4}{|l|}{ Level of Amputation } \\
\hline Transfemoral /Through Knee & $36(40 \%)$ & $53(60 \%)$ & $12(60 \%)$ \\
\hline Transtibial & $47(52 \%)$ & $14(16 \%)$ & $7(35 \%)$ \\
\hline Hip Disarticulation & $3(3.5 \%)$ & $10(11 \%)$ & 0 \\
\hline Bilateral & $4(4.5 \%)$ & $12(13 \%)$ & $1(5 \%)$ \\
\hline \multicolumn{4}{|l|}{ Mobility Before Amputation } \\
\hline Wheelchair bound $\geq 12$ months & $0(0 \%)$ & $27(30 \%)$ & $1(5 \%)$ \\
\hline Wheelchair bound $<12$ months & $1(1 \%)$ & $10(11 \%)$ & $2(10 \%)$ \\
\hline Indoor mobility with aids & $17(19 \%)$ & 30 (34\%) & $9(45 \%)$ \\
\hline Outdoor mobility with aids & $22(24.5 \%)$ & $11(12 \%)$ & $3(15 \%)$ \\
\hline Unaided outdoor mobility & $28(31 \%)$ & $5(6 \%)$ & $1(5 \%)$ \\
\hline Able to walk 3 miles or more & 22 (24.5\%) & $6(7 \%)$ & $4(20 \%)$ \\
\hline
\end{tabular}

Page | 30 
Patients were classified in 2 ways: good/poor function (left columns) or functional/non-functional (right columns), according to SIGAM mobility grade. No patient with a BLARt score $\geq 13$ was able to walk independently (good functional outcome: SIGAM E or F). No patient with a BLARt score $\geq 22$ and only 6 patients with a BLARt score $\geq 17$ were able to walk to any degree (functional outcome: SIGAM $C$ or greater). However there was no clear relationship between low BLARt scores and poor walking 7 ability (SIGAM A-D).

\begin{tabular}{|c|c|c|c|c|}
\hline & \multicolumn{4}{|c|}{ Activity Level at 12 months after amputation } \\
\hline $\begin{array}{l}\text { BLARt } \\
\text { score }\end{array}$ & $\begin{array}{c}\text { Good function } \\
\text { (SIGAM E- F) } \\
(n=22)\end{array}$ & $\begin{array}{c}\text { Poor function } \\
\text { (SIGAM A-D or died) } \\
(n=179)\end{array}$ & $\begin{array}{c}\text { Functional } \\
\text { (SIGAM C-F) } \\
(n=91)\end{array}$ & $\begin{array}{c}\text { Non-functional } \\
\text { (SIGAM A-B or died) } \\
(n=108)\end{array}$ \\
\hline 1 & 3 & 0 & 3 & 0 \\
\hline 2 & 1 & 0 & 1 & 0 \\
\hline 5 & 4 & 3 & 7 & 0 \\
\hline 6 & 4 & 2 & 6 & 0 \\
\hline 7 & 3 & 2 & 5 & 0 \\
\hline 8 & 1 & 10 & 9 & 2 \\
\hline 9 & 1 & 9 & 8 & 2 \\
\hline 10 & 2 & 7 & 6 & 3 \\
\hline 11 & 1 & 5 & 6 & 0 \\
\hline 12 & 2 & 8 & 9 & 1 \\
\hline 13 & 0 & 13 & 10 & 3 \\
\hline 14 & 0 & 16 & 9 & 7 \\
\hline 15 & 0 & 8 & 2 & 6 \\
\hline 16 & 0 & 6 & 4 & 2 \\
\hline 17 & 0 & 9 & 1 & 8 \\
\hline 18 & 0 & 14 & 2 & 12 \\
\hline 19 & 0 & 9 & 0 & 9 \\
\hline 20 & 0 & 8 & 1 & 7 \\
\hline 21 & 0 & 7 & 2 & 5 \\
\hline 22 & 0 & 8 & 0 & 8 \\
\hline 23 & 0 & 5 & 0 & 5 \\
\hline 24 & 0 & 7 & 0 & 7 \\
\hline 25 & 0 & 6 & 0 & 6 \\
\hline 26 & 0 & 5 & 0 & 5 \\
\hline 27 & 0 & 5 & 0 & 5 \\
\hline 28 & 0 & 1 & 0 & 1 \\
\hline 29 & 0 & 1 & 0 & 1 \\
\hline 31 & 0 & 2 & 0 & 2 \\
\hline 32 & 0 & 1 & 0 & 1 \\
\hline
\end{tabular}


1 SIGAM mobility grades:

2 A - non limb user, B - Therapeutic, wears only for transfers, C - Limited/Restricted, walks up to 50m,

3 D- Impaired, walks $50 \mathrm{~m}$ or more with walking aid, E- Independent, walks $50 \mathrm{~m}$ or more without

4 walking aid, $\mathrm{F}-\mathrm{Normal} /$ Near normal walking). ${ }^{39}$

5

6 
Figure 1:

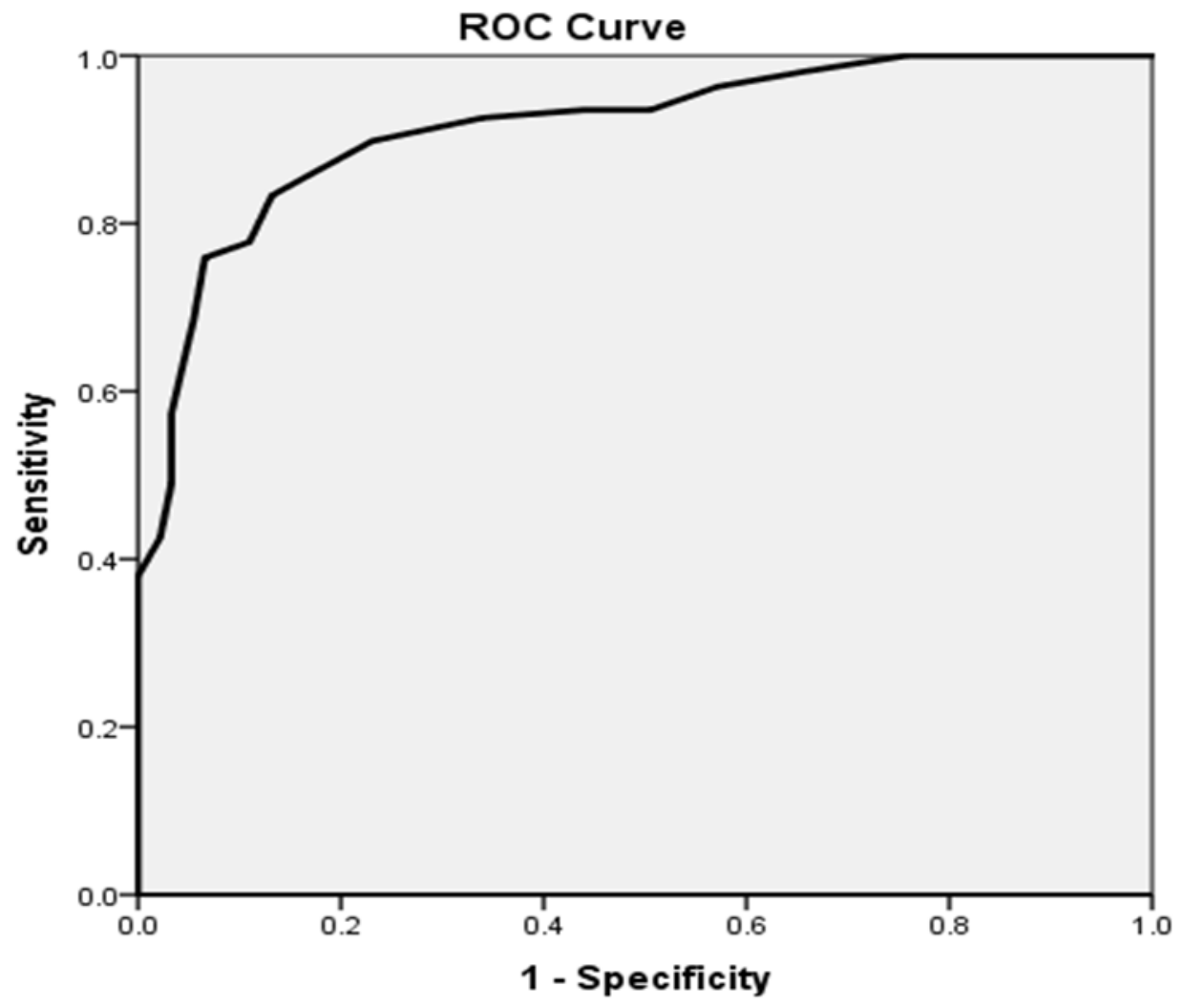

2

3 Figure 1: ROC Curve of BLARt score against likelihood of a non-functional outcome, defined as a

4 SIGAM grade B or below at 12 months after amputation. The area-under-the-curve is 0.914 (SE 0.2, $595 \%$ confidence intervals $0.87-0.95$ ) 